\title{
MIGRAINE.
}

\section{A close Analysis of a further series of one hundred cases.}

\author{
By LT. Col. R. H. ELLIOT, M.D., F.R.C.S.
}

In the autumn of 1932 I read before the Post-Graduate Section of the Fellowship of Medicine a series of three papers on 300 cases of migraine*. There was included as a control another series of nearly 300 cases in which headache and other severe symptoms were present, but which could not be classified as migrainous. These tables contained a great deal of very interesting information, but I felt that the value of the statistics would be much increased if one could add precision to them. To this end I had a table on questionnaire lines drawn up for me, in such a way that merely a cross or a nought or some similar sign could be quickly entered. In this way no point of interest should be missed whilst as little time as possible is lost in making the notes. All the cases were from my private practice, and very great care was taken in compiling the sheets which were afterwards drawn up into tables under a large number of headings. The result was that it was possible to make a number of deductions with far more probability of correctness than in the first series. When I started this earlier series I had no thought of publication, but my findings were of such interest that it seemed worth while to make the further investigations as precise and accurate as possible.

\section{Need for thorough Examination of Eyes.}

A striking feature of the cases is the number of patients who come driven by their doctors and reluctant to have any further examination on the ground that they have already been to able men and have been assured that their eyes were not responsible for their migraine. One must emphasize that in many of these cases the essential factors in the trouble have often been overlooked owing to the examination not being sufficiently methodical and thorough. I make a practice of warning all medical men who ask me to see migrainous patients that I consider it practically useless to undertake such cases unless the subjects are willing to allow me to make three examinations. I once heard a well-known surgeon say before a meeting of medical men that he could examine the refraction of forty children in an hour. I do not think that anybody can really examine a migraine case in less than three half-hours, and some of the half hours may lengthen out to three-quarters of an hour or even to an hour. This matter I have already dealt with in my previous paper, but I want to hammer home my conviction that the principal cause of failure in dealing with migraine is the want of a sufficiently thorough and systematic examination of the ocular conditions. Patients not infrequently volunteer the remark that they have been to one or another distinguished ophthalmologist and that all he did was to examine them in front of types like an optician does. They sometimes add the comment that the surgeon was less thorough than the optician. Too often, the fact that a patient can read $6 / 6$ or better is taken to be a valid reason for the omission of a systematic examination. The astigmometer, the retinoscope, the corneal microscope, and even the ophthalmoscope, are dispensed with, whilst the examination of muscle balance is thought 
superfluous despite the fact that hyperphoria plays a very important rôle in many of these cases.

I hold strongly that a test of the patient's muscle balance should be a routine step in every examination that one makes for refraction. Nor should the fact that the patient has already been examined by several other ophthalmic surgeons, some of them perhaps very distinguished men, absolve the examiner from investigating this point for himself. It is surprising how many cases one meets with in which minus glasses have been prescribed for patients who under a cycloplegic turn out to be hypermetropic. I have a number of records in which this has happened. The plan that we were taught as students to make a routine examination in every case and to enter full notes of our findings is the only safe and proper one. We all make mistakes, however careful we are, but the probability of such misfortunes being multiplied is greatly increased whenever we depart from a routine habit of systematic examination. Another refinement of procedure and a very important one, is to examine the patient three months later when the refraction has had time to settle down under the correction that has been given; it is then possible to correct a hyperphoric or other error both easily and accurately to a degree which is out of the question during the earlier examinations. One is reminded of the way in which the engine of a motor-car runs itself in. In the early stages the patients are inclined to be contradictory when it comes to a refinement of detail, whereas, after the steady use of glasses for some months on end, one gets consistent and definite answers which enable one to prescribe accurately and satisfactorily. Whilst actually writing these lines the truth of this statement has been illustrated in a most marked way by two cases which have returned for a later examination.

I have frequently been told by ophthalmic surgeons that patients will not consent to spend so much time and money on so simple an affair as the testing of refraction. This is far from being always the case though, of course, there are people who object to the expense of so elaborate an examination. I think those who make much of this point fail to realize the terrible amount of suffering and of loss of industrial efficiency which severe headaches and especially migrainous headaches inflict on the victims. It is worth anything that they can afford if only they can get well. Not the least interesting of such cases come from the medical profession. One lady with a very large midwifery practice told me that she was in constant terror of a migrainous attack coming on whilst she was engaged on an obstetric case. It made her whole life uncertain and practically barred her from cultivating a large and lucrative field of practice. Since her refraction has been carefully corrected she has never had a migraine until the attacks started again after some years when she was getting presbyopic. A fresh addition to meet this defect put her right once more. Again, a consulting physician in large practice became so blind during his attacks that he had to be led. He tells me that he now never has an attack of migraine. It would be possible to multiply such instances almost indefinitely. So far from regarding the demand for three visits as unreasonable, migrainous patients are often the first to advise their friends to follow their own example. One cannot take these cases too seriously, and to spend much time and thought over them is thoroughly sound and rational.

There is quite a different condition in which the hesitation to use a cycloplegic comes from the ophthalmic surgeon, namely, when there is a family history of 
glaucoma, or a pulsation of the retinal artery produced on very light fingerpressure, indicating that the normal intraocular pressure is only very slightly above that in the retinal arteries. In all such cases I refuse to make a cycloplegic examination unless the patient will come into a nursing home. It would be nothing short of disaster if one induced an attack of glaucoma when the patient was not under control. I am therefore extremely careful to keep such patients under observation until the pupils contract. I have notes of one case of typical severe migraine in which the patient had signs of threatening glaucoma. I asked her to come into a nursing home, as others had done, and explained my reasons, but she declined to do so and wanted me to go ahead with my examination without taking the precautions I considered necessary. This I absolutely refused to do, so we reached an impasse.

\section{Ocular Causes of Migraine.}

Further experience shows the correctness of the view taken in my earlier paper that there is no special form of defect, whether in refraction or in muscle balance, that is responsible for migraine. Any error of refraction or of muscle balance may bring on attacks provided that the patient has in his nervous system the necessary conditions to produce the characteristic explosions. A very low astigmatism may be responsible. In one case the exciting factor was an error of only $0.25 \mathrm{D}$. with the rule in one eye. Even very low errors of muscle balance may be responsible for continuous headaches and for other symptoms. The dramatic feature of these cases lies in the extraordinary recovery of the patient after the use of suitable prisms, especially for hyperphoria, though sometimes for esophoria and very rarely for exophoria. Whatever the predisposition to migraine attacks may mean, drugs seem hardly to affect it at all. Rarely, patients say this or that drug relieves the condition, but much more often they say that they have tried innumerable remedies without success.

One would expect that if migraine is really in the nature of a nervestorm it would be worked up to regularly, and that the storms would occur at intervals whatever happened, but, as a matter of fact, if you cut off the eye-stimulus which starts the attacks a patient may go quite storm-free for months or years together. This is best illustrated by experience with patients who have lost all their migraine for long periods, but have found the attacks commencing to come back when their correction for presbyopia has begun to be insufficient. A raising of the spherical correction puts them once again in a condition of freedom from their trouble.

A very striking point is the variation in the type of the symptoms presented at different periods of life. The typically migrainous man or woman of today has often suffered from the periodic vomiting of childhood. Again, the advance of life may have brought a greatly decreased, or on the other hand, a greatly increased, severity in migrainous symptoms.

When analysing my first series of 300 cases I felt that I might be underestimating the frequency of occurrence of some of the phenomena met with. My experience with this last group of Ioo cases has shown me that these fears were not illfounded. To begin with, one must remember how difficult it is, even for an intelligent person, to remember the details of any illness, but when that illness is 
of a painful and disabling nature as migraine, often is, it may be very difficult for the patient to study and to record his symptoms. He may feel so desperately ill that he cannot watch the course of events or make clinical observations on himself. Despite this I have found certain signs and symptoms, which I had looked upon as very rare, to be fairly common. This will be illustrated in some of the comments I have now to make.

\section{Predisposing Causes.}

Out of the hundred cases 45 were married women, 27 were unmarried, and 28 were men. This tallies closely with the results of my former and larger statistics and certainly suggests that sexual activity in women is a by no means negligible factor in a predisposition to migraine.

Effect of pregnancy. As I mentioned in my previous paper, there is a wide-spread belief that migraine ceases altogether during pregnancy. This point was carefully studied. Seven of the married women who had had children were quite free from migraine throughout pregnancy. Two more were much relieved. Seven said they were definitely worse. One patient had never had migraine until after the birth of her second child. A number of others were unable to give a definite answer. They had not noticed or could not remember whether pregnancy brought any relief or not. It seems probable that they did not have any striking relief or they would almost certainly have noticed it. The variation in the influence of pregnancy as shown by these recent statistics is decidedly puzzling. So much appears to depend on the idiosyncrasy of the individual patient.

Heredity. I had formed the opinion that migraine was much more often hereditary than my first series of figures suggested. This has been fully borne out in the hundred cases under review, for in 85 of them there was a definite family history of the disease. In I5 of these there was a history of asthma as well. In the remaining 15 eight had a family history of asthma, and in only seven did the investigation of heredity draw completely blank. The difficulty of getting a family history in some of the cases is very great. The patient may know very little of his parents and of the members of their generation, and the small families of the present day often cut down the opportunities for statistics to a hopeless minimum. Nevertheless, the number in which a hereditary history can be obtained is striking. Only in two cases was I able to get a history through four generations, but in many it could be traced in three. Then again, there is a strong connection between migraine and a number of the other allergic conditions such as asthma and hay-fever. I owe my thanks to Dr. Julia Bell for her careful and painstaking analysis of the hereditary factor in some of these people. Her very interesting paper " On the inheritance of Migraine," from the Annals of Eugenics, Vol. V. Parts III and IV, October I933, will well repay careful perusal.

\section{Symptoms.}

Auras. In the previous series eight patients out of the 300 had noticed that they always felt very well the day before an attack and that, indeed, this feeling of 
bien être was a sure warning that a migraine was coming; this suggested to me the existence of a rise in the general blood pressure. I was not, however, prepared to find that a careful enquiry on this point revealed that this particular form of aura was present in no less than 37 out of these roo cases. Of these 37 , six, after being very well the day before, felt limp and ill just before the attack commenced. On the contrary, 9 others "felt rotten" the day before. Ten had auras of visual disturbances, the warnings including scotomata, and blurring of central vision the previous day. One had watering of the eyes and intense pain the night before; one woke thirsty before an attack; two felt hungry. These findings are in close keeping with those of the earlier series.

Sleepiness. My attention has quite recently been called to a symptom which I had never before heard associated with migraine, namely, sleepiness. An able and charming girl aged twenty-five, was sent to me because she fell asleep suddenly and frequently. There was nothing very definite to connect the trouble with migraine except the suddenness of its occurrence and its close association with eye-work. I also had a vague recollection of other migraine patients presenting the same symptom. The back notes were looked up and the following two cases were found.

Over three years ago I saw a married lady aged thirty-seven, with migraine, ache over one eye, nausea and vomiting. She had had periodic sickness as a child and complained that she was "very sleepy during the attacks," which were very frequent in occurrence, sometimes coming on as often as once a week. Cinemas, shopping, etc., brought on the migraine. She had latent hyperopia combined with astigmatism. The correction of her error in refraction cured her sleepiness, and there seemed little doubt that in her it was a migrainous symptom, by which I mean that it was associated with spasmodic interference with the blood supply to a part of her nervous systemin this case the higher centres of the brain.

The third case was a married lady aged twenty-nine and a half years, a typical case of migraine with hemicrania, nausea, vomiting, and one-sided eyeache. She had had periodic sickness as a child. There was great intestinal disturbance with the attacks, and a strong hereditary history. Excitement or watching movement of any kind brought on the attacks, during which she suffered from sleepiness. The physician who referred her to me wrote later to say that the patient reported that she had not had many bad headaches with the attendant symptoms lately. She had added "I am not wearing the glasses all day as prescribed, so really I have not given them a chance."

There is thus justification for looking on the first case I have above mentioned as probably migrainous. Her refraction was carefully corrected, and a prism was used base inward for a high grade of exophoria. This cured her of her trouble. She wrote five months later " You have cured me of my strange affection." When the trouble tended to recur the prisms were increased with satisfactory results.

Hemicrania. In the new hundred cases there were 76 with definite migraine (severe one-sided headache) as against 53.66 per cent. in the earlier series. Of these 76 cases 35 were absolutely sure that the headache was always on one side, either right or left, but always the same in the same individual. In the previous series this figure was only I6 per cent. I4 more said that it almost always came on the same side, but occasionally on the other side. The remaining 27 said that it might start on either side, or that they were uncertain on this point. The great 
interest of these observations lies in the indication of the extreme definiteness of the track along which a migraine storm forces its way. The path is, as it were, prepared for it.

Nausea and Vomiting. Of the hundred cases 2 I complained of nausea alone, whilst 65 more were actually sick, giving a total of 86 per cent. with gastric trouble as against 75 per cent. in the previous statistics. This leaves only I4 per cent. free of any feeling of sickness, an alteration in the former estimate which is undoubtedly due to more accurate note-taking, for it is easy to miss a history of nausea and vomiting unless one important point is borne in mind. As life advances the tendency to severe gastric symptoms unquestionably diminishes. If you ask a patient "Are you sick with the attacks?" he will often say "No", but if you go back to his early history he will tell you that he was formerly sick, but is not now.

Relief of headache, etc. after vomiting was rare, only occurring in twelve cases out of the 65 , and indeed in seven of these twelve relief was only occasionally experienced. This absence of relief after vomiting is in fact characteristic of migraine.

Visual disturbances. The present series shows 77 per cent. in which some interference with vision was noted. Such interferences include spots or small scotomata, hemianopia, dimness of vision from mistiness up to blindness, zigzags, fortification signs, falling stars, revolving wheels, waves, ripples and shimmering like the heat rising off an engine or off hot sand.

Certain people are very rich in these phenomena; in others they are poorly marked; whilst in yet others (23 per cent. in the series) they are not met with at all. A patient rich in these phenomena, especially if he is an intelligent man, may give a very full description of all he sees or has seen, and this will make a powerful impression on the mind of a surgeon taking notes of the case. You have only to add a touch of mysticism in the subject, as I pointed out in my earlier papers, and you get a very arresting history. Eight patients saw falling or shooting stars reminiscent of the Reverend Mother Hildegard's experience. I only had a note of this symptom in 2 per cent. of the former series. "The sensation as of shimmering heat was only noted in just over 4 per cent. of the previous cases, whereas in the new statistics the percentage is double that. The figure for revolving wheels, whether bright or dark in colour, has risen from 2.66 per cent. to II per cent. It is strange that people do not think of mentioning these things unless one goes out of one's way to ask about them. One would think that they are so out of the ordinary that they could not escape comment on the patient's part, especially when one remembers how talkative many of these people are. Not a few of them are so neurotic that one has absolutely to forbid them talking and to insist upon their answering definite questions or one gets nowhere with them. They will chatter about trivial details which are not of the least interest, but they attach the very greatest importance to them. This, of course, is not a universal rule, but the fact remains that a great number of migraine patients are very selfcentred.

Zigzags. In the present series 29 saw zigzags, 2 saw fortification signs, and 4 saw both zigzags and fortification signs, making a total of 35 per cent. against 25 per cent. in my previous series. I ascribe this to the fact that I have been able recently to show my patients the Reverend Mother Hildegard's pictures which 
were not available in many of my earlier cases. This helps them materially to understand what one is talking about. It is interesting that these drawings made eight hundred years ago by an old lady should be of such value to-day in helping us with our diagnosis. It shows how well she both observed and painted.

Hemianopia. I commented in my lectures on the comparative rareness of hemianopia (18.33 per cent.). In the new series it has gone up to 33 per cent. One more point of interest stands out:-in a few cases the blotted-out area of the field was definitely on the opposite side to the migraine.

Blindness. My attention was drawn to the possible intensity of blindness in migraine by the case of a very distinguished physician to whom reference is made in my earlier paper who had to get his wife to lead him away to a quiet spot when he felt an attack coming on. The blindness usually lasted about half an hour. Since his refraction has been carefully corrected he has been entirely free from eye symptoms, though he still gets occasional slight attacks of hemicrania from digestive disturbances. His case led me to make more careful enquiries which were fruitful of results, for 9 per cent. of the new cases said they were hopelessly blind at some time during the attack, whilst 34 more said the interference with vision, though short of actual blindness, was disconcerting and at times very severe. This contrasts with the figure of 4 per cent. of total blindness in the previous 300. A very striking point is that whereas sudden interference with vision from any other cause alarms the patient in the most terrible way, migraine blindness is usually taken very casually. This is evidently due to the fact that years of experience have taught the patients that the symptom is not a serious one.

Coldness. In my previous paper I mentioned that "several patients complained of coldness during the attacks, either of the hands and feet or all over." Careful attention to this point in the last roo cases has elicited the following information. 57 noticed that they were cold during the attacks. Two more were first hot and then very cold, and one felt "dreadfully cold" except that her hands were hot. Two complained of being hot and wet. This leaves a balance of 38 people who either were definitely not cold or hot during the attacks, or who had not noticed this point.

Numbness. The present series shows a complaint of numbness in one part or another in $2 \mathrm{I}$ cases, whereas in the previous 300 only 8 had been detected. The numbness was frequently confined to the hands and feet. An interesting point is that no fewer than I2 had numbness of the tongue and most of these also complained of difficulty of speech, apparently from want of command over the lingual muscles. There were 8 others whose difficulty in speech appeared to have been due to interference with the higher cerebral centres. It was not that they could not say what they wanted, but that they were unable to think clearly. One complained of numbness of one half of the body, the trouble creeping from the hand to the shoulder, the face, the leg, and the whole of one side. Another had one hand and the whole of the lower part of the body affected. Another said that the numbness started at the feet and worked to the top of the head involving the whole body. Three of them complained that they felt too weak to stand. It will be noted that the conditions somewhat resemble serious and permanent affections of the nervous system, but differ from these in passing off completely. The suggestion is that the vaso-motor tract is functionally affected over large areas, thus imitating much more dangerous and important conditions. 
Other nervous phenomena noted were pains in the limbs in 5 per cent., giddiness in 6 per cent., streaming of the nose in 2 per cent. as against one case in the previous 300; occlusion of the nostril in one case, there also being one case in the former series. One had aching at the root of the nose ; one had a feeling of soreness in the neck; three became unconscious suggesting epilepsy; one had aural symptoms; and one had symptoms of cardiac distress as if her heart was going to stop beating. Three had epigastric discomfort; two had acute diarrhœa. Instances of all these symptoms had been noted in the earlier series.

Urinary Symptoms. In the later stages of the earlier series my attention was drawn to urinary symptoms and I was able to collect five in the 300. The interrogation on this point of every single one of the roo cases gave the following results. 7 had anuria followed by polyuria, suggestive of renal vaso-motor constriction with a later reaction towards dilatation. In two polyuria preceded the anuria. $6 \mathrm{com}-$ plained only of anuria, and I2 only of polyuria. Three mentioned that the urine was thick and dark-coloured which probably meant a tendency toward anuria. We thus find no less than 30 per cent. in which the kidneys shared in the signs of the nerve storm. These figures ( $I$ in 60 in the earlier series as against 30 per cent. in the latter) show the great importance of collecting one's data with the aid of a schedule.

Before leaving urinary symptoms I must mention one case in which a young man found that his attacks of migraine were ushered in by the involuntary passage of urine at night.

\section{Influence of Diet.}

A very systematic effort has been made in the later series to find out how far food and alcohol influence the incidence of migraine attacks and what benefit is conferred by the use of various remedies. I have long expressed my strong conviction that the correction of errors of refraction or errors of muscle balance stops the tendency to the attacks and enables the patient to lead an ordinary life. Indeed, there are cases in which the careful fitting of glasses has allowed patients to return to a life normal in all respects inclusive of the ingestion of foods or of alcohol which previously had been dangerous. At the same time, it is obvious that it is wise in such cases to widen the margin of safety by careful attention to every detail of the patient's life. Even if he can now take certain foods or alcohol with impunity so long as he wears the glasses, one cannot be sure that this happy state of affairs will always continue, and the motorist's rule "Use all of your hairpin bend" is a valuable one here. Three of the patients were benefited by taking alcohol during an attack and two by taking food, whereas most of them hated the sight of anything to eat or drink. 22 of them found that alcohol brought on the attacks; Io blamed fats and cream; 6 blamed chocolates; 2 beef; 2 sugar; 2 eggs; 2 coffee; and I tinned food. There were thus 25 who were inclined to blame food and 22 who blamed alcohol out of the hundred.

Few things are worse than the faddism which exalts teetotalism, vegetarianism and a number of other "isms". In dealing with migraine as with so many other disease conditions, the important thing to find out is what is the best form of diet for the individual patient. I ask each one to make a list of what he takes to eat daily at each meal, and at the same time to keep in another column a record of any attacks of migraine that develop. Only in this way can reliable data be obtained. Speaking of perhaps quite another condition, I have often 
been struck with the favourable influence of alcohol during convalescence from serious eye operations on elderly people, especially old ladies who have been teetotalers or next door to it all their lives. A small quantity of alcohol may add to the enjoyment of their food and prove the very best of tonics. I merely mention this to show how intensely individualistic patients are. We must never lose sight of this point in treating migraine or any other condition.

\section{Results.}

When I gave the original lectures a natural question asked me was, "Can you give figures showing the percentage of cases cured?" I have made a very strong effort to follow up my patients and to get as reliable statistics as possible.

There is one point which must be carefully remembered. Nearly all of these cases had been to another ophthalmic surgeon beforehand, and quite a number of them had been to several specialists. They were thus not at all on a footing with most of the cases which one tries to examine by the aid of statistics. In other words, they were exceptionally difficult cases. Many of them had met with bitter disappointment. The failure to obtain relief from glasses which had previously been ordered or from drug treatment which had been prescribed made them very bad subjects from the point of view of morale. They did not expect to get good results. Indeed, some of them were quite unpleasant in the early stages and made it clear that they only came under protest. They thought that it was a fad of their doctor when he demanded a fresh examination of their eyes. Under these circumstances the results attained must, I think, be conceded to have been very satisfactory.

Thirty-four were definitely cured. These included several medical men and women. A number of them wrote with an enthusiasm which would surprise anyone who was not aware of the terrible physical disability imposed by migraine. Some of the communications were from medical men who had been afraid they would have to give up their profession because they were becoming so increasingly unreliable. Other doctors wrote of patients, who had been unable to lead normal lives, and who were now taking long motor journeys and exposing themselves to various hardships without the least sign of their old trouble. I venture to quote from two of these letters which are, if possible, more dramatic than the rest. The first was from a doctor who, when abroad, had met a patient whose attacks were brought on by motoring, cold weather, and high altitudes; he said "I happened to take her over a mountain road in my car. I was unaware that previously this was to her an impossibility. Instead of making her very ill, she positively enjoyed it." A layman wrote "I am always a bad traveller. I went by aeroplane to Hamburg . . . . . blinding rain and thunderstorms, nerves anything but calm. In spite of all this excitement I had no headache and I really counted on one."

A further twenty-one reported a great improvement in their condition short of complete cure. Some of these have not, however, been long enough under observation to make one feel confident that everything possible has been done.

As I have said above, a lot of patience is required on the part of the surgeon and of the subject, and it is often necessary to alter first one factor and then another in the glasses. It will be readily understood that when a patient has latent hyperopia, a small degree of astigmatism, perhaps against the rule, an error in muscle-balance, and possibly some presbyopia, it is difficult to be sure which 
element or elements in the case are responsible for the continuance of some part of the trouble. In such a case as the one just outlined it may be a mistake to correct the whole of the latent hyperopia. Or again, it may be that the total astigmatism shown under a cycloplegic is considerably greater than that which the patient wears with comfort on the third examination. To give the full correction may here again be a great mistake. The objective estimation of the hyperphoria may be considerably greater than that which will add to the patient's comfort when the eye has recovered from the cycloplegic and returned to its normal. To mention one last point, the amount of presbyopia which one finds, if fully corrected, may bring the reading distance up to $\mathrm{I}_{3}$ or I4 inches, but the patient may firmly declare that this is much closer than he wants and may demand a glass enabling him to read at 15 or I6 inches. What is one to do? Much depends on experience, and even that may not always guide one exactly aright. Experiment may be needed first.

Three patients owned to a slight improvement, but had not altogether lost the migrainous symptoms. I had a fourth in this category, but whilst writing this paper I have heard from the patient's doctor that he has "derived tremendous benefit." "This improvement dates from last February when I was able to add a prism to the correction I had given him five months previously.

Four refused to wear glasses, declaring that they would rather have headaches and keep their looks. The astonishing part of this attitude is that it may and frequently does come from people whom one would never look at twice if one met them casually. Not all of them are ladies. A man who had very severe attacks every two days would not consent to wear glasses. His doctor's comment was "I regret the patient was such a fool," an observation with which one could only cordially agree.

Eight refused to have a cycloplegic. I think I have already made it clear that, in my opinion, an examination without this precaution is of comparatively little value. One died. Six have gone abroad and cannot be traced. One was sent to a gynæcologist as her troubles probably lay in his department. There were two who said they were no better. One of these I am still working on; I think a large factor is his adolescence. The other merely said that she was no better and would not return for a further test.

This leaves us with twenty cases which it has not been possible so far to follow up. One thing is quite certain, whereas a large number of people will grumble if their glasses are not absolutely satisfactory, an even greater number will fail to report a really good result. Over and over again, I have met with such people years afterwards, and reproached them for not having let me know of the relief which the treatment had brought them. The standard answer has been "I found the glasses so satisfactory that I did not worry any further about it," and this in spite of the fact that they had most definitely promised to send me a report one way or the other.

There is yet another source of fallacy in our statistics. As I have repeatedly said above, there are quite a number of migraine cases whom one cannot get absolutely right at the first attempt. Some of these lack confidence in the surgeon and will not give him the chance of altering the glasses. Instead of persevering, they either go to some one else, or simply discard the glasses. They thus throw away a chance of a happy result. 